\title{
Campaign to End Fistula
}

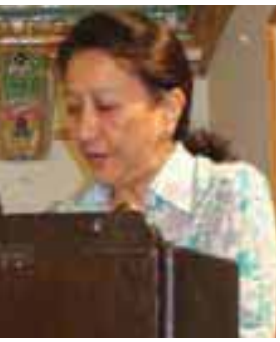

Prof Dr Kundu Yangzom

Dept of Obst/Gyn, Patan Hospital, PAHS, Nepal

\begin{abstract}
"Obstetric fistula" what does it mean?
"Mismanaged labour. ." (Dr Vinit Sharma, Reproductive Health Advisor,
\end{abstract}

"Failure......my failure, our failure as an obstetrician, as health personnel, as fellow women, as a community, as a country" (Dr Sayeba Akhter, fistula expert, Bangladesh)

Vesico Vaginal Fistula (VVF): the most common cause of VVF in developing countries is obstetric; other causes include iatrogenic, traummatic, neoplastic, and post radiotherapy. Obstretric Fistula (OF) is a devastating condition following childbirth injury, that leaves the afflicted woman miserable with urine continuously leaking from the vagina - making her embarassed, isolated, ashamed of herself and socially unacceptable. Luiz DeMercado, 1597, a physician of Valladolid seems to have been the first to use the term "fistula" rather than the usual word "ruptura" when he wrote, "What an empty and tragic life is led by the affected women and how great are their embarassment - uncontrolled urine runs from the fistula with ease." James Marion Sims, the father of American Gynaecology was believed to be the first to recognize and successfully treat women with VVF. However, references to fistula date back to around 2000 B. C. when Professor D. E. Derry (1935) described the pelvis of five women of the 11th Dynasty in Egypt. Queen Henhenit, one of the wives of King Mentuhotep II was of special interest. Professor Derry examined her mummy: "the injury was considered to be a tear from the vagina to the bladder due to the abnormally narrow pelvis, through which the child had to be dragged by force. The vagina was discovered crushed between the distended bladder and the rectum". Thus Queen Henhenit is documented to be the most antique VVF sufferer which probably occurred during her labor - finally resulting in her death. Over the years different surgeons have reported different techniques with varying success rates. The contribution of Sims, Emmet and Bozeman, for the first time put the technique of fistula surgery on a plane never before realized or even anticipated, so success became much more predictable (Zacharin). The first fistula hospital was founded by James Marion Sims in 1855 in New York, which was later renamed Woman's Hospital after fistula was eradicated. This site is presently occupied by the Waldorf Astoria Hotel, Park Avenue, New York. The second fistula hospital was started in Adis Ababa, Ethiopia (1975), which is now the biggest fistula hospital in the world. Following that, fistula hospitals have been started in Nigeria, other parts of Africa. In Asia Fistula Hospital have been started in Bangladesh, Pakistan, finally now in Nepal there are plans for a "fistula ward" at Patan Hospital and "fistula corner" at the Maternity Hospital in Kathmandu. Thankfully OF has recently begun to gain international attention and various donor agencies have gotten invovled. A global "Campaign to end Fistula" led by UNFPA (United Nations Population Fund) is helping to prevent and treat fistula in more than 30 countries in Africa, South Asia and the Arab region. Launched in 2003, the
Correspondence

Dr. Kundu Yangzom DGO, SITCOG

Prof \& Head Dept of Obs/Gyn Patan Hospital

PAHS

Phone : 9841549666

Email : kundu_yangzom@yahoo.com 
campaign focuses on three key areas of intervention: preventing fistula, treating affected women, and helping women return to full and productive lives after surgery. The exact prevalence of fistula in Nepal is not known. Patan hospital has had the largest series of fistula treated over the last twenty years (Journal of SAFOG Sept-Dec 2010) The Patan Hospital Initiative was started by Dr Silvia Scholz, a german missionary Obstetrician/ Gynaecologist who worked in Patan Hospital, Nepal, for more than 12 years. After attempting some unsuccessful repairs and hearing the story from these young girls, she was particularly affected by the innocence, traummatic impact and the isolation this condition drove them to. So, Dr Scholz initiated the fistula management at Patan Hospital and since then, even after she left to her home country, Germany, fistula management has continued at Patan Hospital. Since late 2010, UNFPA Nepal has actively been involved with the OF initiative.....involving an NGO - WOREC (Non Government Organistion Women's Rehabilitation Centre, Nepal), Family Health Division Nepal, Nepal Society of Obstetricians and Gynaecologists, Patan Hospital Lallitpur, BPKHIS (B.P.Koirala Institute of Health Sciences, Dharan)...... resulting in three fistula camps being conducted: first and third camps at Patan Hospital and the second at BPKHIS, providing free treatment to 11,16 , and 25 fistula sufferers. Experts were invited from France and Bangladesh. Other camps were also conducted at another rural center. A case mapping of the fistula cases treated at Patan Hospital was done in December 2010: The results showed that these cases came from all over Nepal and some from across the Indian border. It was surprising to see so few cases from the remote areas, where the geographical terrain makes it inaccessible to proper obstetric care......... whether these women did not survive obstructed labor and its complications, or whether these afflicted women are still out there in their remote homes, dejected, neglected, ignorant and too poor to realise that there is a hope for cure. is still an enigma.

I appeal to all my colleagues let us spread the word around, increase public awareness about this condition and make an aggressive approach in identifying fistula afflicted women......so that we may be able to offer them a new hope for life. As we all know, fistula treatment does not require expensive medicines or high tech equipment, it needs patience and a team of dedicated nurses and expert doctors to cure them.

Let us all join hands to eradicate this problem in Nepal and restore dignity to our women. "Obstetric Fistula is not only a challenge to the surgeon and team, but more to the society where they occur." 